\title{
INCLUSÃO DIGITAL E AS POLÍTICAS PÚBLICAS: QUAL O PAPEL DA ESCOLA E DO PROFESSOR?
}

\author{
Marilice Botelho Martins Oliveira* \\ Elizabete Velter Borges** \\ Terezinha Bazé de Lima***
}

\begin{abstract}
RESUMO: O analfabetismo digital cresce cada vez mais nesta era tecnológica e precisamos rever o papel da escola e do professor para lidar com os novos perfis de nossos alunos. Pensando nisso, o presente artigo tem como objetivo identificar, analisar e conceituar qual o papel do professor e da escola para minimizar o analfabetismo digital. Tendo como metodologia a pesquisa bibliográfica em que foi possível obter respostas para as indagações construindo e reconstruindo novos conceitos sobre o analfabetismo digital, por meio de respaldos teóricos de, Antonio Sousa; John Palfrey e URS Gasser; Antonio Carlos Gil; Iêda Maria Debona Soldatelli; Angela Fernandes Melo; João Fernandes Lindote Júnior e Alan Silus. Os dados pesquisados foram coletados em artigos científicos, livros e pesquisas em sites conceituados. Como resultado observou-se a importância das políticas públicas serem postas em prática proporcionando estrutura física as escolas como laboratórios de informática e manutenção dos mesmos, bem como capacitação do corpo docente, para que esta sequência de etapas seja possível minimizar o analfabetismo digital.
\end{abstract}

ABSTRACT: Digital illiteracy grows more and more in this technological age and we need to review the role of the school and the teacher to deal with the new profiles of our students. With this in mind, this article aims to identify, analyze and conceptualize the role of the teacher and the school to minimize digital illiteracy. Having as methodology the bibliographic research in which it was possible to obtain answers to the questions, constructing and reconstructing new concepts about digital illiteracy, through the theoretical backing of, Antonio Sousa; John Palfrey and URS Gasser; Antonio Carlos Gil; Iêda Maria Debona Soldatelli; Angela Fernandes Melo; João Fernandes Lindote Júnior and Alan Silus. The researched data were collected in scientific articles, books and research on reputable websites. As a result, it was observed the importance of public policies being put in place, providing schools with physical structure, such as computer labs and their maintenance, as well as training the faculty, so that this sequence of steps is possible to minimize digital illiteracy.

PALAVRAS CHAVES: Analfabetismo digital, Professor, Escola.

KEY WORDS: Digital illiteracy, Teacher, School.

\section{INTRODUÇÃO}


O analfabetismo digital, tema muito discutido hoje nas escolas, cresce cada vez mais nesta era tecnológica, trazendo significativas diferenças nos perfis das crianças, necessitando, por isso, rever o papel da escola e do professor no século XXI. Nesse sentido, o objetivo dessa pesquisa foi identificar, analisar e conceituar qual a importância do papel do professor, independentemente da modalidade de ensino na qual atuará e da escola, para minimizar as causas e consequências do analfabetismo digital. No Brasil, o avanço tecnológico teve início entre os anos de 1958 a 1975, começando o mundo a mudar rapidamente. As pessoas passaram a ter acesso a computador e a linhas telefônicas, trocar documentos, ler notícias e enviar mensagens umas às outras. Todas essas mudanças ocorreram em um curto espaço de tempo de maneira significativa, gerando mudanças na maneira de viver e se relacionarem.

As escolas estão defasadas e não possuem equipamentos suficientes e atuais para toda a comunidade escolar. Nela, os próprios professores se preocupam, pois acreditam estarem despreparados para lidar com a nova geração digital, visto que as antigas habilidades não despertam mais a atenção dos alunos. Dessa forma, nos deparamos com o atual cenário de analfabetos digitais. Uma realidade em que a inclusão digital precisa ser pensada, reorganizada e posta em prática.

$\mathrm{O}$ analfabetismo digital criou o analfabeto funcional da era atual: muitas tecnologias foram disponibilizadas à população seja no ambiente escolar, no trabalho ou no ambiente doméstico. As empresas de hardware e software trabalham intensamente criando e desenvolvendo ferramentas que facilitem a vida das pessoas. O governo, por sua vez, disponibilizou linhas de crédito facilitando a aquisição dessas ferramentas, e equipou as escolas com laboratórios de informática, fixo e móvel. A maioria da população hoje, independentemente da idade, utiliza celular com Internet, netbook, laptops, notebooks, tv smart. Mas, a principal ação não foi pensada, a preparação do usuário para que este pudesse usufruir a melhor maneira dos benefícios do produto que tinha em mãos. Assim, percebe-se que os alunos estão totalmente despreparados para cuidar de suas identidades e privacidades no mundo virtual.

Nesse sentido, identificar, analisar e conceituar qual o papel do professor e da escola para minimizar o analfabetismo digital são os objetivos da referida pesquisa, que será bibliográfica. Pois, de acordo com Gil (2008, p.50), a pesquisa bibliográfica é desenvolvida a partir de material já elaborado, constituído principalmente de livros e artigos científicos.

A pesquisa bibliográfica proporcionará respostas para as indagações construindo e reconstruindo novos conceitos sobre o analfabetismo digital, baseando-se nos teóricos: 
Antonio Sousa; John Palfrey e URS Gasser; Antonio Carlos Gil; Iêda Maria Debona Soldatelli; Angela Fernandes Melo; João Fernandes Lindote Júnior e Alan Silus.

Contudo, para minimizar o analfabetismo digital é necessário analisar o envolvimento e conhecimento dos que estão conectados como pais, professores e a escola, pois têm um papel fundamental na construção da formação desta nova geração que busca rapidez, agilidade, interação virtuais, imediatismo; só dessa maneira todos os envolvidos poderão contribuir para a formação de alunos autônomos e responsáveis diante de tanta evolução tecnológica com segurança.

Sendo assim, é a escola, instituição que fornece processo de ensino para discentes (alunos), com o objetivo de formar e desenvolver cada indivíduo em seus aspectos culturais, sociais e cognitivos, após um trabalho de capacitação e de informação estará apta para trabalhar com as novas tecnologias, proporcionando momentos de aperfeiçoamento e capacitação para sua equipe docente.

\section{ANALFABETISMO DIGITAL}

Com o passar dos anos a informática foi ganhando espaço nos diferentes ambientes. As escolas foram equipadas com laboratórios fixos e móveis, alguns com sistemas operacionais pagos outros livres com acesso à Internet, mas que já se encontram sucateados e obsoletos por não receberem a devida manutenção.

Por este prisma, a informática proporciona diferentes recursos e ferramentas na maneira de ministrar as aulas, mas os docentes, que são os mediadores do conhecimento, deparamse com a falta de treinamento / capacitação em utilizar essas metodologias, promovendo o analfabetismo digital.

E, quando se fala em analfabetismo digital, fala-se em uma sociedade despreparada para ler o conteúdo digital, utilizar os softwares aplicativos como editores de texto, planilha de cálculos, apresentação de slides e manter em segurança seus perfis na rede web. As crianças são curiosas e interativas, se encantam com o mundo virtual navegando sem limites pela Internet, por outro lado, temos os professores atarefados que alegam não terem tempo e curiosidade pelo mundo virtual. Falta organização, apoio, planejamento por parte das escolas para proporcionar a inclusão digital e social dos professores. 
É importante destacar que a tecnologia pode ser um grande aliado do professor, e nesse sentido Unesco apud Sousa argumenta que:

\begin{abstract}
O computador é uma ferramenta que pode auxiliar o professor a promover aprendizagem, autonomia e criatividade do aluno. Mas, para que isto aconteça, é necessário que o professor assume o papel de mediador da interação entre aluno, conhecimento e computador, o que supõe formação para exercício deste papel. Entretanto, nem sempre é isto que se observa na prática escolar. Estudos sobre o tema apontam que a formação do professor para a utilização da informática nas práticas educativas não tem sido priorizada tanto quanto a compra de computadores de última geração e de programas educativos pelas escolas (UNESCO apud SOUSA, 2017, p.55).
\end{abstract}

As aulas tradicionais precisam ser revistas, os professores carecem de capacitação, para que assim, possam despertar o interesse dos alunos pela aprendizagem, na qual muitas ferramentas podem ser utilizadas e trabalhadas em sala proporcionando um novo método com segurança e praticidade. "A possibilidade de pesquisar, ler e conhecer sobre os mais variados assuntos navegando na internet confere ao aluno um novo perfil de estudante, que exige também novo perfil de professor" (FREITAS, 2010, p.348).

A escola necessita de planejamento para apoiar e proporcionar tempo para a inclusão digital dos professores, só assim poderiam conhecer e pôr em prática ferramentas que auxiliariam no desenvolvimento de suas disciplinas. De acordo com Palfredy, Gasser (2011, p.18), os professores se preocupam com o fato de eles próprios estarem em descompasso com seus alunos Nativos Digitais. E, cabe mencionar que os alunos utilizam desde muito cedo os meios eletrônicos sem o devido cuidado, muitas vezes ainda nem alfabetizados são e manuseiam com destreza o celular, por exemplo, sem a supervisão de um adulto colocando em risco a sua identidade e a de seu responsável.

O uso da tecnologia começa em casa, onde temos como responsáveis os pais que, muitas vezes, por não conhecerem ou não saberem como utilizar, não veem com bons olhos o uso do vídeo game, do celular, por exemplo, pois acreditam que atrapalham os estudos, mas hoje já se tem outro julgamento, em que os jogos passam a ser utilizados como ferramenta para estimular o raciocínio, resolução de problemas, estimular a criatividade, conhecer outros assuntos e interagir socialmente.

\title{
1.1 A ERA DIGITAL
}


Um sistema computacional consiste num conjunto de dispositivos eletrônicos (hardware) capazes de processar informações de acordo com um programa (software). Podemos conceituar hardware como qualquer parte de um sistema de computador que pode ser vista ou tocada. Já o software é um conjunto de instruções eletrônicas que dizem ao computador o que ele deve fazer para atender as necessidades do usuário (peopleware).

No decorrer do tempo os hardwares evoluíram em sua funcionalidade diminuíram em tamanho e custo passando a fazer não só de espaços empresariais como educacionais. Então, há exatos 74 anos nasce o primeiro computador, o ENIAC desenvolvido durante a Segunda Guerra, e, desde então, as primeiras tecnologias de informação vêm sendo aprimoradas, até chegar no Brasil. "A informática educativa no Brasil tem início em 1993, mas com raízes históricas em 1970, quando Universidades da época produziram um seminário com tema base à utilização da informática para enfatizar a educação em Instituições de Ensino Superior" (SOUSA, 2017, p. 19).

Pensando nessa Nova Era o Ministério da Educação, em 1997, criou o Programa Nacional de Tecnologia Educacional (ProInfo), para promover o uso da tecnologia como ferramenta de enriquecimento pedagógico no Ensino Público Fundamental e Médio. A partir de 12 de dezembro de 2007, mediante a criação do Decreto $\mathrm{n}^{\circ} 6.300$, foi reestruturado e passou a ter o objetivo de promover o uso pedagógico das tecnologias de informação e comunicação (TICs) nas redes públicas de educação básica.

O grande desafio agora seria com o apoio dos governos federais, estaduais e municipais para subsidiarem as instituições de ensino para que possam capacitar o docente para saberem utilizar as máquinas e as novas tecnologias equipar e dar manutenção nos laboratórios de informática das escolas, revendo, assim, os paradigmas para atender o novo discente mais autônomo e curioso.

Nesse sentido, os nativos digitais têm o computador como um aliado para o desenvolvimento e aprendizagem do aluno explorando sua criatividade e autonomia, mas, para que isto ocorra necessita-se de professores capacitados dispostos a reinventar suas práticas pedagógicas para mediar este aprendizado.

O avanço da tecnologia tornou o acesso ao conteúdo e pesquisa mais democrática e ao alcance de todos. O professor não deve preocupar-se com isso, e sim instigar e mediar este conhecimento que agora ganha rapidez e agilidade. Por meio das novas ferramentas o docente pode atrair cada vez mais o interesse do aluno, explorando o seu melhor e auxiliando-o na sua formação como cidadão crítico e formador de opinião. 
Para que o sucesso docente ocorra é fundamental, além da formação acadêmica, se atualizar, para que possa ter domínio sobre os recursos digitais que irá trabalhar, pois contará com a capacitação contínua para aprimorar seus conhecimentos desenvolvendo suas habilidades e competências.

Assim, vamos à busca da inclusão digital dos meios e recursos físicos, digitais, humanos e sociais, que o professor irá dispor a seu favor para poder proporcionar acesso significativo as novas tecnologias, mediando assim o aprendizado dos alunos na tentativa de minimizar o analfabetismo digital.

\subsection{INCLUSÃO E EXCLUSÃO DIGITAL}

Inclusão digital é o processo de democratização do acesso às tecnologias da informação, de forma a permitir a inserção de todos na sociedade da informação. A inclusão digital é a leitura e compreensão dos meios digitais, saber utiliza-los, manusear da melhor forma as ferramentas, usufruindo de todos os recursos que o mesmo disponibiliza com segurança é a porta de entrada para o mundo digital.

Quem não lê e não domina os conteúdos da informática, não sabe ou não utiliza a Internet é considerado um analfabeto digital, e ele é uma consequência da exclusão digital, pois segundo Mello (2016), a causa desse analfabetismo é associada à "exclusão digital", denunciada em todo o mundo como a forma mais moderna de violência aos direitos de cidadão, e modalidade sutil de manutenção e ampliação das desigualdades.

A exclusão digital amplia as desigualdades sociais, pois nem todos têm acesso às tecnologias e não possuem celular, computador com acesso à Internet, ou não sabem utiliza-la, interpretar sua linguagem, usufruir dos recursos que ela disponibiliza. E será na escola que este indivíduo encontra a possibilidade de desenvolver habilidades e competências para trabalhar com esta ferramenta, que irá proporcionar novas descobertas, interação social, superação de desafios e novas aprendizagens. Melo (2016, p.27), afirma que "abordar questões como cidadania, inclusão digital e democracia são paradigmas traçados pelas instituições escolares, respaldadas pelas legislações, que visam a formação de uma sociedade com oportunidades igualitárias”.

\section{PAPEL DA ESCOLA}


$\mathrm{Na}$ era digital utilizamos como ferramenta de trabalho o hardware, este por sua vez para realizar suas funções necessita de softwares, que processam informações, estas uma vez coletadas transformam-se em dados digitais. Os nascidos na era digital, mesmo antes da alfabetização, já conhecem a linguagem digital bits, sigla para Binary Digit, em português Dígito Binário, geralmente usada na computação e teoria da informação, é a menor unidade de informação que pode ser armazenada ou transmitida, um bit assume somente 2 valores, 0 ou 1. (Disponível em: https://www.infowester.com/bit.php. Acesso em: 08 de jul. 2020)

Tudo poderá ser processado e transformado em linguagem de máquina e ganha velocidade na Internet, um bom exemplo são os e-books, revistas, jornais, softwares educacionais, videogames. As crianças passam a ter acesso ao mundo digital por curiosidade e esperteza, mas sem orientação e mediação na interação com estes recursos.

A escola passa a ter um papel fundamental na mediação deste aprendizado, pois será por meio dela que muitos terão o seu primeiro contato com o mundo virtual. As instituições de ensino como mediadora deste aprendizado, devem equipar-se com laboratórios de informática e ofertar aos seus docentes cursos de capacitação, para utilização dos hardwares e softwares que serão trabalhados com os discentes.

O uso da tecnologia faz parte do cotidiano, seja familiar ou escolar, existe uma grande discussão em torno deste tema que busca auxiliar no como fazer, como ensinar, como mediar este conhecimento por meio das redes sociais ou das ferramentas didáticas. Porém, é preciso lembrar que, para muitos dos discentes, será seu primeiro contato com mundo tecnológico.

Como afirma Soldatelli (2020, p.4)

[...] é preciso avaliar a melhor forma de se trabalhar o uso das tecnologias como material de ensino aprendizagem, pois ainda é complexo para os professores, muitas vezes também se torna difícil para alguns estudantes, sendo que uns estão muito além das tecnologias e outros "engatinhando" no mundo tecnológico. 
Com o apoio da escola, os professores podem realizar um excelente trabalho, tendo como recurso o uso das tecnologias, sendo ferramentas que auxiliem nas atividades didáticopedagógicas, oportunizando um grande aprendizado. Segundo Melo (2016, p.27) a introdução dos microcomputadores na sala de aula ou na escola, por meio de laboratórios de informática, podem representar uma possibilidade mais eficaz de lidar com alguns tópicos do ensino.

A escola que possui um laboratório de informática equipado e conta com um quadro de professores capacitados para trabalhar com os softwares ali disponíveis, tem um grande diferencial no aprendizado de seus discentes, pois o computador, além de exercer seu princípio básico de entrada, processamento e saída de dados, passa a ser visto como meio de comunicação.

E é por meio da escola que será possível ensinar o uso das novas tecnologias aos discentes, demonstrando a eles o quanto pode ser relevante para sua vida aquele aprendizado, não só para o lazer, mas para tarefas do cotidiano, como fazer compras, serviços bancários, pesquisa relacionado ao aprimoramento do conhecimento.

Pois, é por meio das mídias que se tem o mundo digital, desde uma simples pesquisa a uma visita ao museu, as aulas podem ganhar reforços on-line, muitas universidades, por exemplo, já trabalham assim. São diversos os softwares disponíveis para se trabalhar com textos, gráficos, cálculos, slides, vídeos, animações; ferramentas estas que podem complementar as aulas tornando-as mais atrativas para a geração de hoje.

A escola é um espaço que auxiliará na minimização do analfabetismo digital, por meio de políticas públicas que proporcionem computadores, recursos digitais, conteúdos educacionais, adequando assim, o espaço educacional, capacitando o corpo docente para utilizar os laboratórios e suas tecnologias.

\section{PAPEL DO PROFESSOR}

Neste novo cenário educacional que se encontra o professor, é preciso reinventar-se em busca de novas práticas pedagógicas que despertem o interesse dos discentes na aprendizagem, por meio da interação aluno-computador-professor, um mundo digital que pode ser explorado construindo e reconstruindo novos conceitos com interação, pesquisa e segurança. 
O professor como mediador do aprendizado deve capacitar-se para utilizar as novas tecnologias, através de treinamentos ofertados pela escola e de outros realizados por seu próprio interesse, dando assim continuidade na sua formação continuada, desenvolvendo capacitando-se, para assim aplicar suas práticas com excelência.

Segundo afirma Júnior, Silus (2020, p. 2)

[...] entender e compreender o funcionamento dessa tecnologia é fundamental para que sua aplicabilidade seja de forma mais satisfatória possível, assim é "dever" do docente buscar alcançar essa excelência, com formação continuada, a fim de se preparar e capacitar para a aplicação dessa importante ferramenta no processo de ensino-aprendizagem.

A democratização de ensino é um processo vinculado à expansão das oportunidades educacionais e, consequentemente, das condições estruturais de ensino-aprendizagem oferecidas no espaço escolar. Segundo Júnior, Silus (2020, p.8) a democratização e a popularização do acesso às tecnologias da informação pelas diversas camadas sociais da sociedade criaram um novo paradigma de construção do conhecimento.

Pois, o processo de ensino aprendizagem mediado pelo uso das tecnologias na qual o docente oportuniza a construção de novos saberes, desperta o interesse dos discentes para pesquisar, produzir, criar e reinventar. Para Júnior, Silus (2020, p.14) o professor passa a exercer um papel de mediação entre o saber e o aluno, contribuindo assim para a facilitação da obtenção do conhecimento, usando ferramentas e recurso para o alcance desse objetivo.

Com está postura o professor capacitado aguça a curiosidade dos alunos a fim de que se tornem pessoas críticas, capazes de entender, analisar e levantar dúvidas que estudadas geram novos conhecimentos ao tema estudado. Neste processo, a escola conta com o docente que terá um papel fundamental, mediar o aprendizado preparando o discente para atuar com a cultura da informação e conhecimento. A interação e a competição que as novas tecnologias despertam nos discentes são dois aspectos que eles adoram, tendo como consequência o envolvimento e interação, melhorando a aprendizagem e diminuindo a evasão escolar.

A democratização do ensino é papel da escola, sendo esta uma das suas funções sociais, pois vivemos em uma sociedade que isola pessoas, e o mundo digital apresenta-se como um espaço diferenciado, pois une pessoas num mesmo espaço, só que virtual. 
O professor quando se apropria deste novo papel e compreende seu todo, questiona o seu modo de ser, pensar, agir e comunicar com esta nova geração, preocupa-se com a aprendizagem do discente, em que a mediação do uso das novas tecnologias tem de responder a quatro questionamentos na organização de seu planejamento pedagógico como: saber o que, como e porquê e quando utilizar as tecnologias disponíveis na construção do aprendizado, assim de posse destas respostas poderão fazer modificações significativas no processo de aprendizagem dos discentes. Para Júnior, Silus (2020, p.14) essa preparação é fundamental na correta aplicação do recurso e, assim, podem orientar a formação do aluno no seu contexto social e cultural, valorizando o elemento humano e não a máquina.

A utilização do computador torna-se uma nova prática pedagógica dentro do processo ensino-aprendizagem, em que o professor articula e media a aprendizagem por meio de novos processos, oferecendo ao discente, inovação, dinamização, participação, interação na aplicação das atividades e na aquisição de novos conhecimentos.

\subsection{O USO DA LINGUAGEM TECNOLÓGICA}

As práticas pedagógicas estão sendo invadidas por uma série de novidades eletrônicas, como lousas digitais, data show, redes sociais, e-mail. As novas práticas na educação ainda não consolidadas no seu todo, despertam uma vontade de experimentar o novo e é na sala de aula que acontece o desafio, já que ela traz novos elementos alterando dinâmicas sociais criando um maior diálogo entre professor e aluno.

O professor que utiliza como recurso o uso da tecnologia para desenvolver suas aulas deve estar preparado para os imprevistos, pois a rede pode travar, a Internet pode parar de funcionar e, muitas vezes, haverá discentes com maior conhecimento que o dele em determinada ferramenta, mas, em contrapartida, haverá o que não sabe ligar o computador. Caberá ao professor estar atento e mudar sua estratégia como direcionar o aluno conhecedor daquela ferramenta para outra tarefa, para que não perca o interesse, valorizando o conhecimento, podendo este contribuir com o aprendizado dos colegas.

O uso das tecnologias em sala envolve planejamento, disciplina e organização. Necessitamos de um ambiente favorável onde o conhecimento do aluno e do professor se fundam em busca de novas maneiras de pensar e de fazer, concebendo novos trabalhos, gerando criatividade e novos conceitos por meio dos recursos tecnológicos. 
O desafio do professor é ser mediador da alfabetização digital, pois é a única máquina que pode avaliar, reorganizar, modificar e estabelecer relações significativas na sociedade de informação, compreendendo assim, o contexto econômico, político, social e cultural. Assim Soldatelli instiga a uma reflexão acerca da linguagem humana e a linguagem máquina

\begin{abstract}
Assim, a linguagem que devemos levar ao aluno deve fazer com que ele tenha capacidade para observar, perceber, descobrir e refletir sobre o mundo; bem como interagir com seu semelhante por meio do uso funcional das linguagens, desenvolver a competência do educando no uso da língua para a solução de problemas cotidianos, possibilitar o acesso à produção cultural da humanidade e também à participação plena no mundo letrado. (SOLDATELLI, 2020, p. 4).
\end{abstract}

Por meio dos projetos pedagógicos o professor pode mediar a inclusão digital, proporcionando o uso das tecnologias na construção de novos conhecimentos, respeitando o ritmo de aprendizagem dos seus discentes. A introdução do aprendizado das novas tecnologias no ambiente escolar faz-se urgente para esta nova era digital, como menciona Júnior e Silus apud Bueno (2014, p. 69-70) "essas tecnologias estão redesenhando a educação, criando novas oportunidades de ensino. Essas facilidades possibilitam a exploração dos ambientes virtuais, permitindo o acesso a uma ampla diversidade de atividades que professores e alunos podem realizar".

As escolas precisam incluir em seu projeto político pedagógico os recursos tecnológicos, orientando os professores para que reorganizem suas práticas com o auxílio das mesmas e este terá um grande desafio de resgatar, ressignificar o papel da escola, lugar onde as crianças aprimoram seus conhecimentos.

Ainda, em relação a essa geração tecnológica Júnior e Silus discorrem que:

Logo esse fato acarreta uma necessidade do ambiente escolar em se reformular, haja vista que passarão a receber jovens, provenientes de uma sociedade digitalizada e mais crítica, assim torna necessária mudanças de atitude e ação, perante a didática e a prática pedagógica desenvolvida pelo professor. (JÚNIOR, SILUS, 2020, p. 10). 
A linguagem de programação conhecida por Internet mudou e está mudando o planeta, pois por meio dela tem-se a informação nas mãos, mas é preciso de um mediador para auxiliar a transformar estas informações em conhecimento, e o professor, além de mediar este aprendizado, deverá ser conhecedor destas ferramentas, pois só assim saberá o momento de utilizá-las como recurso em sala, desenvolvendo as habilidades e competências necessárias para um aprendizado eficaz.

Esta nova prática pedagógica traz consigo experiências, interação e comunicação promovendo o conhecimento de forma autônoma e prazerosa. Quando se integra o uso das tecnologias nas práticas pedagógicas significa proporcionar uma educação de qualidade seja de vida ou de inclusão social e digital.

\section{POLÍTICAS PÚBLICAS}

Contamos com as políticas públicas de educação que são programas ou ações criadas pelos governos para colocar em prática medidas que garantam o acesso à educação para todos os cidadãos. Como expressa o artigo 205 da Constituição da República Federativa do Brasil (1988) "a educação, direito de todos e dever do Estado e da família, será promovida e incentivada com a colaboração da sociedade, visando ao pleno desenvolvimento da pessoa, seu preparo para o exercício da cidadania e sua qualificação para o trabalho".

Para Melo (2016, p.07),

[...] assim é possível compreender que o papel das políticas públicas voltadas à inclusão digital é criar e socializar novas formas de utilização das tecnologias digitais nas escolas públicas brasileiras, para ampliar o processo de inclusão digital escolar e promover através delas o uso das TICs em caráter pedagógico.

Pensando na inclusão digital, na necessidade do uso de computadores nos espaços escolares, faz-se visível a aprendizagem dos alunos, para que estes possam estar atualizados diante das novas tecnologias e saberem como usufruir com qualidade e segurança todos os recursos que esta ferramenta oferece no seu conjunto dentre software, hardware e tecnologias de informação e comunicação (TCIs) e a capacitação dos discentes para a mediação desta aprendizagem. 
Para que haja uma compreensão de como ocorreu a implantação das Politicas Públicas sobre a implantação dos programas de inclusão digital, há que se fazer uma retrospectiva histórica: Em 1971 o Brasil dá seus primeiros passos na informática educativa, através de pesquisas resultando no Programa Educom coordenado pelo MEC quando, pela primeira vez, cogitou o uso do computador no ensino de física. E através do Programa de Ação Imediata em Informática na Educação de $1^{\circ}$ e $2^{\circ}$ graus o governo visa focar a preparação de novas políticas, avaliar o Educom, formar e fomentar a produção de softwares destinados a capacitar professores.

Em 1992, o MEC cria o Programa Nacional de Informática na Educação (Proninfe) tendo o objetivo de instruir e levar a informática a todos os sistemas públicos de ensino, programa conceitualmente muito elevado, mas sem a realização de nenhuma ação.

Pensando em melhorias nasce em 9 de abril de 1997 o Programa Nacional de Tecnologia Educacional (Proinfo), um programa educacional criado por meio de uma portaria $n^{\circ}$ 522/MEC, para promover o uso pedagógico das tecnologias de informática e comunicações (TICs) na rede pública de ensinos fundamental e médio.

Em 12 de dezembro de 2007, o Programa Proinfo ganha novos objetivos ampliando e especificando as ações por meio do Decreto 6.300, visando a formação de professores, a disponibilização de conteúdos educacionais, infraestrutura dos laboratórios, suporte técnico e manutenção dos laboratórios. Para alcançar os objetivos propostos o governo brasileiro cria um projeto denominado Um Computador por Aluno (UCA), cujo objetivo é distribuir um computador móvel para estudantes das escolas públicas.

No gráfico a seguir o Centro de Estudos sobre as Tecnologias da Informação e da Comunicação (Cetic), divulga a pesquisa TIC Educação 2016, notícia divulgada pelo site G1 escrita por Clara Campoli em 03/08/2017, a pesquisa mostra dados como os principais hardwares utilizados para acessar a Internet nas escolas públicas e privadas.

Gráfico 1- Dispositivos utilizados pelos alunos, 2017 


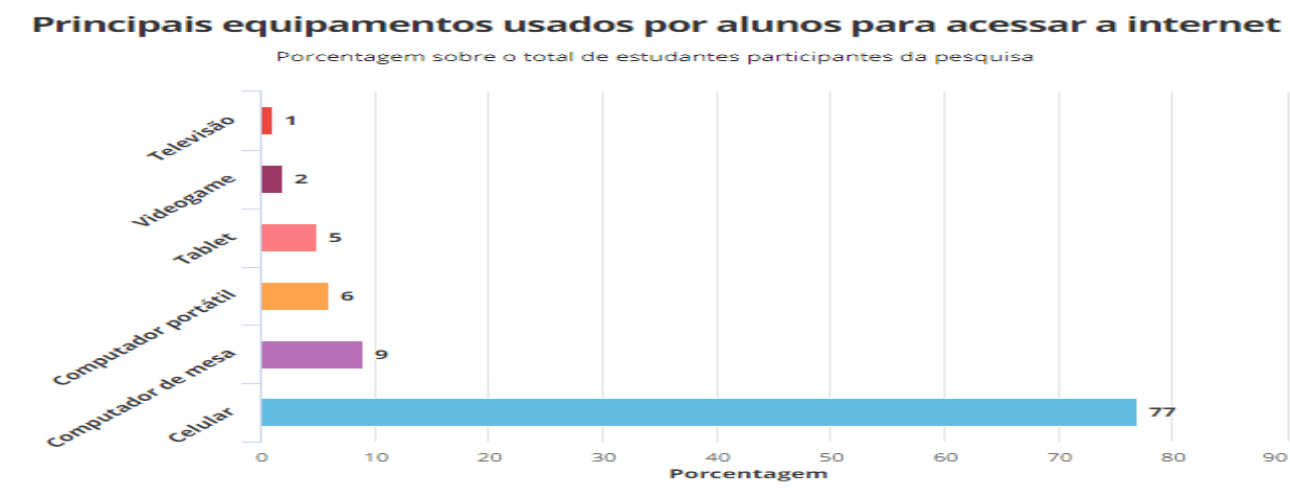

Fonte: https://g1.globo.com/retrospectiva-g1/2017/. Acesso em: 12 de jul. 2020.

Principais equipamentos usados por alunos para acessar a Internet.

Com o objetivo conectar todas as escolas públicas à Internet, por meio de tecnologias que propiciem qualidade, velocidade e serviços para incrementar o ensino público no país, o governo cria o programa Banda Larga nas Escolas em 04 de abril de 2008; mantendo essas conexões inicialmente de forma gratuita até o ano de 2025.

Em 2011 o Ministério de Educação e Cultura sente a necessidade de acompanhar e monitorar possíveis problemas no programa Proinfo desenvolvendo, então, o projeto Proinfodata, um programa de Inclusão Digital Brasileiro que visa o desenvolvimento de plataformas baseadas em mídias digitais como forma de apoiar e atuar de maneira preventiva e tem como objetivo acompanhar o estado de funcionamento dos laboratórios Proinfo deste programa.

Em 20 de dezembro de 2017, foi homologado o documento de Base Nacional Comum Curricular em conformidade com o PNE (Plano Nacional de Educação) e LDB (Lei de Diretrizes e Bases da Educação Nacional), que:

[...] é um documento de caráter normativo que define o conjunto orgânico e progressivo de aprendizagens essenciais que todos os alunos devem desenvolver ao longo das etapas e modalidades da Educação Básica, de modo a que tenham assegurados seus direitos de aprendizagem e desenvolvimento. (Base Nacional Comum Curricular - BNCC, 2017, p.08).

Em novembro de 2017, o governo lança o Programa Inovação Educação Conectada (PIEC), que visa a universalização do acesso à Internet em alta velocidade até 2024, para 
fomentar o uso pedagógico das tecnologias digitais na educação básica, promover ações como auxiliar que o ambiente escolar esteja preparado para receber a conexão de Internet, destinar aos professores a possibilidade de conhecerem novos conteúdos educacionais e proporcionar aos alunos o contato com as novas tecnologias educacionais.

E, dentre as dez competências gerais da Base Nacional Comum Curricular, temos a Cultura Digital que busca compreender e utilizar tecnologias digitais de informação e comunicação de forma crítica, significativa, reflexiva e ética; para que se possa acessar e disseminar informações, produzir conhecimentos e resolver problemas com $\mathrm{o}$ protagonismo.

Como mostra a TIC Educação 2016, estamos com as escolas públicas e privadas estruturadas com laboratórios de informática fixo e móvel com acesso à Internet, mas nem todos estão sendo utilizados como recurso nas práticas pedagógicas, já que aponta um baixo número de professores da rede pública em relação aos da rede privada que utilizam os meios tecnológicos em suas atividades pedagógicas mesmo as escolas estando estruturadas, como é possível verificar no gráfico.

Gráfico 2 - Presença e uso do laboratório de informática.

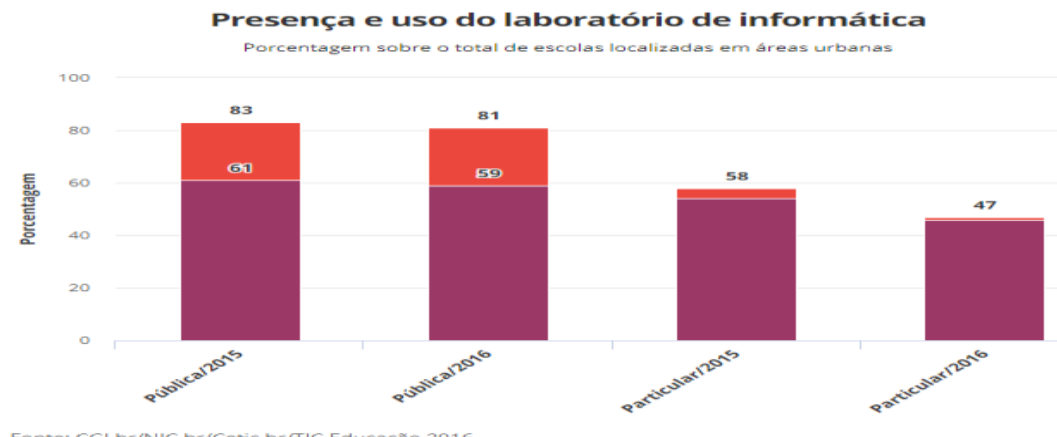

Fonte: CGI.br/NIC.br/Cetic.br/TIC Educação 2016.

Presença e uso do laboratório de informática.

Assim, pode-se observar neste breve histórico o quanto são importantes as políticas públicas e como estas podem influenciar e beneficiar as comunidades por meio da utilização das tecnologias digitais nas escolas públicas brasileiras. Só a partir do desenvolvimento delas será possível realizar a inclusão digital proporcionando bem-estar, desenvolvimento cultural, educacional, contribuindo, assim, de forma significativa na qualidade de vida dos indivíduos. 


\section{CONSIDERAÇÕES FINAIS}

A informática na educação começou sua trajetória há cerca de cinquenta anos. Através de pesquisas, projetos e programas ganhou espaço de uns vinte longos anos até os dias atuais quando se faz presente na maioria das escolas sejam públicas ou privadas, mas mesmo com o apoio das políticas públicas para a informatização destes espaços ainda temos algumas barreiras a enfrentar como a exclusão digital e a capacitação de professores.

Para minimizar o analfabetismo digital precisamos incluir digitalmente os discentes, que nem sempre disponibilizam destes recursos em suas residências, tendo acesso às tecnologias só nas escolas. Necessita-se capacitar, estimular o corpo docente para incluir os recursos tecnológicos em suas práticas pedagógicas, promovendo assim uma transformação na educação. Pois, manter as escolas públicas equipadas com laboratórios que recebam sua devida manutenção é requisito fundamental para incluir digitalmente o currículo a ser desenvolvido pelos docentes, usufruindo de recursos digitais com qualidade.

A era digital busca integrar e diminuir as desigualdades sociais, por meio das tecnologias. A integração aluno, computador e professor descreve uma nova era de inovação de práticas pedagógicas, na qual as informações passam estar disponível a todos, por meio da Internet com a mediação do professor o discente amplia seus conhecimentos, aprimora seu aprendizado e constrói seus conceitos.

Só será possível minimizar as causas do analfabetismo digital com a efetiva ação das políticas públicas nos espaços escolares, com o comprometimento da equipe diretiva, apoiando e capacitando os docentes para a mediação da utilização destas novas tecnologias, que buscam o desenvolvimento de nosso discente formando assim cidadãos éticos, participativos e formadores de opinião.

\section{REFERÊNCIAS}

CIVIL, Presidência da República Casa. Constituição da República Federativa do Brasil de 1988. em:<http://www.planalto.gov.br/ccivil_03/constituicao/constituicao.htm>. Acesso em: 04 de maio de 2020.

EDUCAÇÃO, Ministério. Perguntas frentes sobre o programa banda larga nas escolas. Disponível em: $<$ http://portal.mec.gov.br/busca-geral/193-secretarias- 
112877938/seed-educacao-a-distancia-96734370/15914-perguntas-frequentes-sobre-oprograma-banda-larga-nas-escolas>. Acesso em: 04 de maio de 2020.

EDUCAÇÃO, Fundo Nacional de Desenvolvimento da. Projeto um computador por aluno

(UCA).

Disponível

em:<https://www.fnde.gov.br/index.php/programas/proinfo/eixos-de-atuacao/projetoum-computadro-por-aluno-uca>. Acesso em: 04 de maio de 2020.

EDUCAÇÃO, G1. 52\% das instituições de educação básica usam celular em atividades escolares, aponta estudo da Cetic. Disponível em: $<$ https://g1.globo.com/educacao/noticia/52-das-instituicoes-de-educacao-basicausam-celular-em-atividades-escolares-aponta-estudo-da-cetic.ghtml>. Acesso em: 04 de maio de 2020.

EDUCAÇÃO, Fundo Nacional de Desenvolvimento da Educação Ministério da. PROINFO Programa Nacional de Informática na Educação. Disponível em:<http://www.fnde.gov.br/programas/proinfo>. Acesso em: 04 de maio de 2020.

FARIAS, Gilberto. Introdução a computação. As gerações de computadores. Disponível em: $\quad<$ http://producao.virtual.ufpb.br/books/camyle/introducao-a-computacaolivro/livro/livro.chunked/index.html >. Acesso em: 05 de maio de 2020.

FREITAS, Maria Teresa. Letramento digital e formação de professores. Educação em Revista. v. 26. n 03. Belo Horizonte - MG, dez, 2010. p.335-352. Disponível em: $<$ https://www.scielo.br/scielo.php?script=sci_arttext\&pid=S0102-

46982010000300017>. Acesso em: 05 de maio de 2020.

GIL, Antonio Carlos. Métodos e técnicas de pesquisa social. 6. ed. São Paulo: Atlas, 2008.

JÚNIOR, João Fernandes Lindote; SILUS, Alan. Integração das tecnologias digitais nas práticas docentes: Olhares contemporâneos. Interletras, ISSN 1807-1597. Qualis. v.8. ed.30. outubro 2019/março 2020. p.1-18. Disponível em: $<$ https://www.unigran.br/dourados/interletras/ed_anteriores/n30/conteudo/artigos/04.pdf $>$. Acesso em: 05 de maio de 2020.

MELO, Angela Fernandes. A inclusão digital na escola para a erradicação do analfabetismo tecnológico. Revista Multidisciplinar de Ensino, Pesquisa, Extensão e Cultura do Instituto de Aplicação Fernando da Silveira (CAP-UERJ), Rio de Janeiro, v.5, n.10, p. 21-30, dezembro 2016. Disponível em: < https://www.epublicacoes.uerj.br/index.php/e-mosaicos/article/viewFile/26618/18985>. Acesso em: 05 de maio de 2020.

PALFREY, John; GASSER, Urs. Nascidos na era digital: entendo a primeira geração de nativos digitais. 1. ed. Porto Alegre: Grupo A, 2011.

PRODANOV, Cleber Cristiano; FREITAS, Ernani Cesar de. Metodologia do trabalho científico [recurso eletrônico]: métodos e técnicas da pesquisa e do trabalho acadêmico. 2. ed. Novo Hamburgo: Feevale, 2013.

PROINFODATA. Coleta de dados do projeto PROINFO/MEC de inclusão digital nas escolas públicas brasileiras. Disponível em: <http://proinfodata.c3sl.ufpr.br/> Acesso em: 05 de maio de 2020. 
SOLDATELli, Iêda Maria Debona. Práticas pedagógicas no cotidiano do ensino médio: mundo digital e suas múltiplas facetas no cenário escolar. Interletras, ISSN 18071597. Qualis. v.8. ed.31.abril/setembro 2020.p.1-16. Disponível em: < https://www.unigran.br/dourados/interletras/conteudo/artigo/18.pdf $>$. Acesso em: 05 de maio de 2020.

SOUSA, Antonio Idêrlian Pereira de. Analfabetismo Digital na Educação, Revista: EaD \& Tecnologias Digitais na Educação. v.4, n.5. Dourados- MS, 2016. ISSN 2318-4051. p. 52-57. Disponível em: <http://webcache.googleusercontent.com/search?q=cache:COfxk653pu4J:ojs.ufgd.edu.b r/index.php/ead/article/download/5493/3706+\&cd=1\&hl=pt-BR\&ct=clnk\&gl=br $>$.

Acesso em: 05 de maio de 2020.

SOUSA, Antonio. A informática e a exclusão digital [livro eletrônico]. 2. ed. Dourados, MS: edição do autor, 2017.

\footnotetext{
*Acadêmica do Curso de Pedagogia do Centro Universitário da Grande Dourados-UNIGRAN. https://orcid.org/0000-0002-5102-0082.

** Professora Mestre em Educação do Curso de Pedagogia do Centro Universitário da Grande Dourados UNIGRAN e orientadora desse trabalho. https://orcid.org/0000-0002-2016-3777.

***Professora Doutora em Educação do Curso de Pedagogia do Centro Universitário da Grande Dourados - UNIGRAN e orientadora desse trabalho. https://orcid.org/0000-0002-2000-5031.
} 